\title{
Ciudad y lucha: la plaza como altavoz social. Parámetros urbanos y sociopolíticos en la ocupación del espacio público iberoamericano
}

Javier Navarro-de-Pablos. Universidad de Sevilla, Sevilla, España.
Daniel Navas-Carrillo. Universidad de Sevilla, Sevilla, España.
María-Teresa Pérez-Cano. Universidad de Sevilla, Sevilla, España.

RESUMEN | El espacio público ha sido tradicionalmente refugio civil en periodos de convulsión social. Siendo el motor y filtro que equilibra las relaciones sociales entre ciudadanos, es ocupado, discutido, reclamado y transgredido. La globalización de las redes sociales ha impulsado el desplazamiento de las demandas sociales hacia el mundo virtual. Sin embargo, la plaza sigue constituyendo, en la mayoría de las expresiones reivindicativas, el símbolo físico en el que se encuentra y reconoce la colectividad. El presente artículo pretende determinar, a través de una metodología gráfica extrapolable, qué parámetros urbanos y sociopolíticos marcan la capacidad de un espacio para acoger manifestaciones o revueltas. Estas coreografías sociales representan, ante todo, un acto de transformación y apropiación de la ciudad, reafirmando la figura del ágora como lexema atemporal. Recorriendo tres casos de estudio del arco iberoamericano -en contextos de dictadura, estabilidad y crisis- se observan singularidades diferenciales y ritos comunes inherentes al comportamiento humano.

PALABras Clave | espacio público, movimientos sociales, conflicto social.

ABSTRACT | Public space has traditionally been a refuge for communities in periods of social upheaval. Being the engine and filter that balances social relations between citizens, it is occupied, discussed, claimed, and transgressed. The globalization of social networks has driven the displacement of social demands towards the virtual world. However, the square continues to be the physical symbol in which the collectivity finds and recognizes itself in most of the claims. This article aims to determine, through an extrapolable graphic methodology, which urban and socio-political parameters mark the capacity of space to receive demonstrations or revolts. These social choreographies represent, above all, an act of transformation and appropriation of the city. They reaffirm the figure of the agora as a timeless lexeme. Through three Ibero-American case studies-in contexts of dictatorship, stability, and crisis-differential singularities and common rites inherent in human behavior have been observed.

KEYWORDs | public space, social movements, social conflict.

Recibido el 13 de marzo de 2019, aprobado el 15 de julio de 2019.

E-mails: J. Navarro, fnavarro@us.es | D. Navas,dnavas@us.es | M. Pérez, tpcano@us.es 


\section{Introducción}

En el marco del complejo y heterogéneo abanico de situaciones y contextos específicos que acontecen en la ciudad contemporánea, este artículo trata de definir parámetros comunes en la ocupación del espacio público iberoamericano desde el último tercio del siglo xx. A través del mapeado de lugares ocupados por sectores poblacionales acuciados por problemas sociales y económicos, se observa cómo emergen vectores comunes que trascienden del mero hecho político-reivindicativo o geográfico. Desde las Madres de la Plaza de Mayo bonaerense a las protestas del Movimiento 15-M en Madrid, se pretende responder a varias preguntas planteadas a raíz del texto El derecho a la ciudad escrito por Lefebvre en 1968. Asumiendo como válidas las últimas revisiones conceptuales en torno a la reconquista del espacio público por parte de la ciudadanía como lugar de reconocimiento colectivo (Harvey, 2012; Monreal, 2016; Sevilla-Buitrago, 2015), se propone indagar en la condición física del fenómeno. Para ello, se definen unos niveles de "rebeldía" del espacio urbano, partiendo del axioma de que el espacio público es genéticamente un elemento en disputa.

La etimología de la expresión "Estado de Derecho" hace referencia a un Estado de justicia, contrapeso de los regímenes despóticos basados en una "fe" sujeta al poder (Barret-Kriegel, 1989). Su consolidación y éxito en las democracias occidentales tras la Segunda Guerra Mundial fue construyendo, análogamente, unos "Estados del Bienestar" que cubrían las necesidades básicas de los ciudadanos, en ocasiones puestas en crisis por la realidad del sistema neoliberal. Ambas expresiones, promovidas en parte por un cierto "mercado de productos ideológicos" (Chevallier, 2015), corren el riesgo de caer en el vacío semántico, en una desocupación conceptual. Al ritmo de esta conversión en expresiones cliché, la crisis económica global ha introducido en las áreas urbanas una componente disruptiva: la indignación. La ocupación de los espacios públicos simbólicos urbanos se ha convertido en una práctica habitual, que a pesar de la novedad en las "coreografías" colectivas tiene unas sólidas bases primitivas que relacionan ciudad y disputa en una simbiosis fundacional.

En un movimiento acompasado, mientras las políticas de austeridad económica y recesión alejan ciudadanía y política, el sentimiento de pertenencia y propiedad del espacio público en cuanto patrimonio colectivo ha crecido. El revulsivo de la macrocrisis económica, lejos de aminorarse tras la estabilización bursátil y financiera, ha asentado una respuesta social coordinada y globalizada: movimientos como \#Metoo o las protestas en contra del crecimiento de los populismos no difieren en su formalización de los movimientos obreros tradicionales del siglo xx, pero sí muestran un triple cambio simbólico: uno, en cuanto a la legitimidad de la ocupación del espacio público como derecho asumido y consolidado; otro a una diversificación temática de las protestas apoyadas en las herramientas digitales como plataforma de pre-ocupación física (Torre, 2015); y en tercer lugar, a un carácter global y universal que transforma problemas localizados geográficamente en fenómenos compartidos. ¿Es posible determinar aquellos parámetros materiales e inmateriales del espacio público capaces de acotar su potencialidad de ser ocupados?, ¿marca la transversalidad temporal y geográfica una singularidad a la hora de transformar esos espacios? 


\section{Parametrización de un fenómeno global}

El análisis de las características políticas y sociales de los "lugares-altavoz", de sus contornos urbanos y espaciales, constituye el hilo discursivo de la presente investigación, que se apoya en un estudio comparado de diez casos en los que la relación entre el espacio público y la reivindicación ha tenido una especial trascendencia: plaza de Mayo (Buenos Aires), plaza Tahrir (El Cairo), plaza Taksim (Estambul), plaza Zucotti o Wall Street (Nueva York), Alexanderplatz (Berlín), Puerta del Sol (Madrid), plaza de Tiannanmen (Pekín), plaza de la Paz (Barranquilla), plaza de la Encarnación o Setas (Sevilla) y plaza de la Constitución (Santiago de Chile). ${ }^{1}$ En concreto, el artículo se centra en tres ejemplos iberoamericanos: la plaza de Mayo de Buenos Aires (1977), la plaza de la Paz de Barranquilla (1992-2005) y la Puerta del Sol de Madrid (2011), ejemplificando circunstancias sociopolíticas heterogéneas (dictadura militar, equilibrio democrático y contexto de crisis), espacialidades divergentes (plaza de poder militar, plaza civil y plaza comercial) y contextos municipales bifurcados (metrópoli dispersa, ciudad media, metrópoli compacta). Tratándose de tres casos de centralidad urbana, sin la que no podrían ostentar el simbolismo suficiente para erigirse como símbolos reivindicativos, en su cuantificación numérica encontramos que se trata de tres realidades físicas paradigmáticas, reflejo de situaciones espaciales diferentes, tanto en superficie (plaza de Mayo con $26.350 \mathrm{~m}^{2}$, plaza de la Paz con $19.120 \mathrm{~m}^{2}$, y Puerta del Sol con $11.800 \mathrm{~m}^{2}$ ), como en número de manifestantes (plaza de Mayo con 100 a 200 personas, plaza de la Paz con 5.000 a 20.000 personas, y Puerta del Sol con 79.000 a 120.000 personas). Esta caracterización expresa la imposibilidad de trazar reglas previas de comportamiento y ocupación, puesto que mayores superficies parecen no implicar mayores afluencias, al igual que se establecen relaciones no proporcionales entre manifestantes y repercusión internacional (Figura 1).

Tras el análisis comparativo según los parámetros espaciales, sociopolíticos y de contorno urbano -detallados a continuación-, se ha procedido al estudio en profundidad de cada caso a través de un análisis paramétrico según una secuencia de valores escalares de 0 a 4 (Figura 2). Tras este acercamiento cuantitativo, se ha procedido a realizar un estudio gráfico de los flujos de ocupación de cada plaza, a fin de visualizar las condiciones espaciales en la convergencia de la ritualidad cotidiana-reivindicativa. 


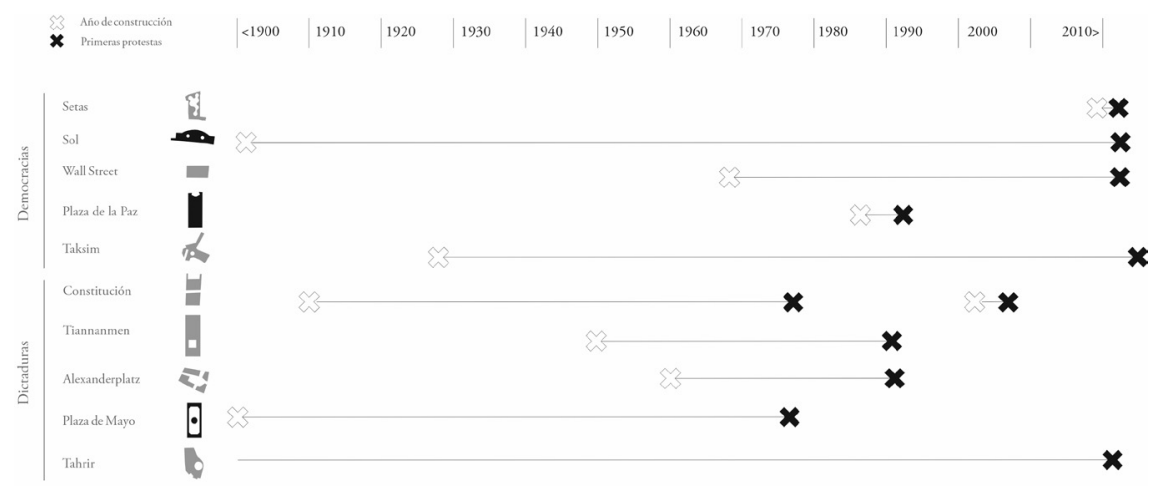

FIGURA I | Comparación de los casos de estudio seleccionados, puestos en relación según su año de construcción, el estallido de las protestas, y el régimen político en el momento de la ocupación

Nota EN NEGRo, Los CASOS DE ESTUdio PRESENTAdos

FUENTE ELABORACIÓN PROPIA

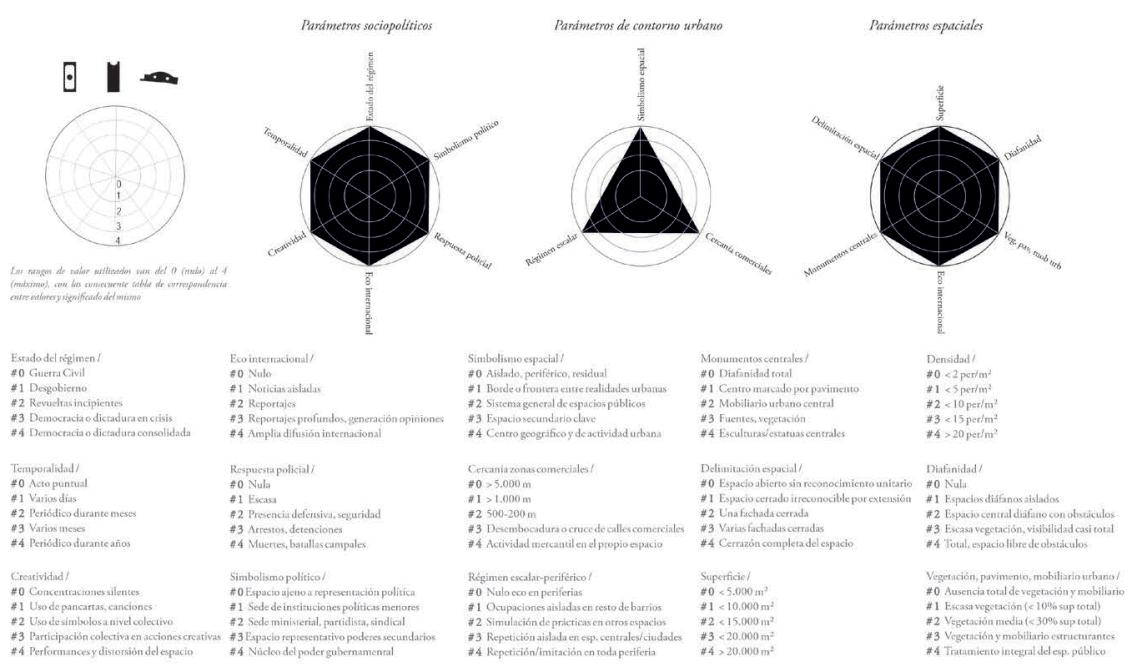

FIGURA 2 | Enumeración de los parámetros elaborados para la evaluación de las condiciones sociopolíticas, urbanas y espaciales de cada caso

FUENTE ELABORACIÓN PROPIA

\section{Parámetros espaciales}

La elección del espacio en el cual desarrollar las protestas guarda una evidente relación con su capacidad para congregar una multitud considerable con el objetivo ulterior de crear imágenes rotundas cuya divulgación mediática desencadene la 
presión necesaria para la consecución de una mayor repercusión. En esta cadena de acciones y efectos, la intervención del poder cuestionado resulta crucial para el devenir de las protestas: la respuesta de los diferentes gobiernos y regímenes ha sido mayoritariamente la dispersión de las ocupaciones, alegando la preservación del ya citado "Estado de Derecho". Intervenciones desproporcionadas o visualmente cruentas han revertido generalmente en situaciones paradójicas: los colectivos organizadores se han fortalecido, solidificando el axioma fundacional de la propiedad colectiva del espacio público.

Siguiendo el planteamiento de Escalada y Castro (2016), se ha considerado la interacción de tres sujetos clave: manifestantes, fuerzas de seguridad y medios de comunicación. La variabilidad de correlaciones entre estos tres actores conduce a la aparición de múltiples escenarios marcados por la intensidad de poder y escenificación, a la vez que se encuentran condicionadas por las características espaciales de cada caso. Partiendo de estas premisas iniciales y habiendo definido los agentes sociales y gubernamentales participantes, se han revisitado los aún vigentes argumentos de Sitte (1980) en torno a los parámetros que inciden en la percepción del espacio público. Tras ello se ha procedido a sintetizar los criterios de elección del espacio reivindicativo (Figura 3), introduciendo elementos contemporáneos procedentes de las propuestas de Gehl (2014). Como resultado de este proceso de cribado teórico se han tenido en cuenta, para su aplicación analítica, los siguientes parámetros sustanciales: i) la proximidad simbólica o física del espacio público elegido, con el objeto o sujeto de la convocatoria (posición); ii) su visibilidad (diafanidad/ dimensión); iii) su capacidad de acoger grandes aglomeraciones (superficie física); iv) accesibilidad, cualidad espacial y proximidad a espacios comerciales (habitabilidad del espacio).
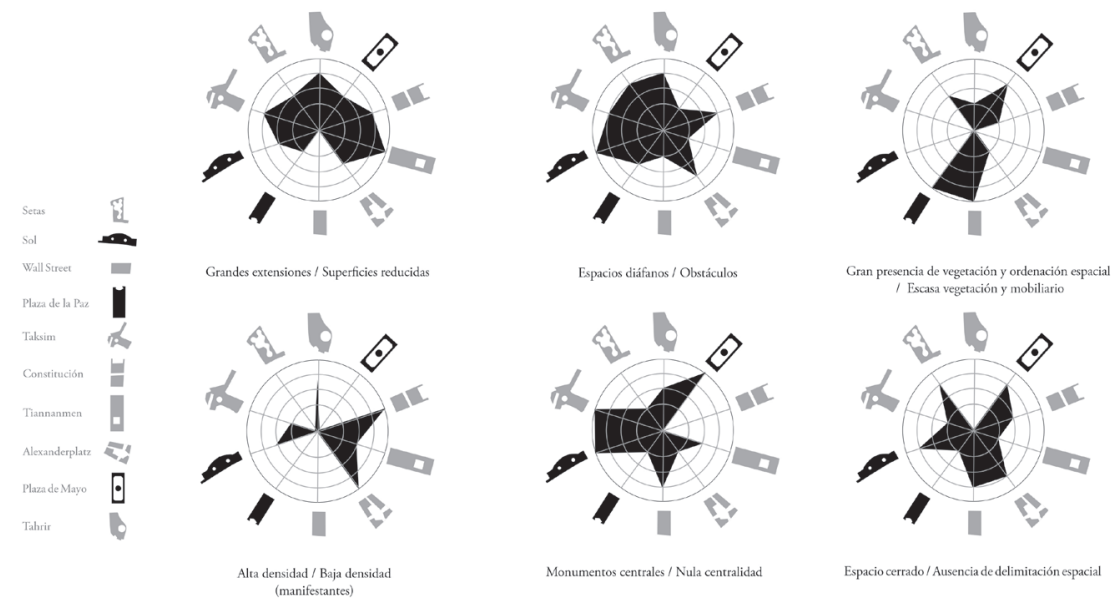

FIgURA 3 | Comparación de los casos de estudio según sus parámetros espaciales NOTA EN NEGRO, LOS CASOS DE ESTUdio PRESENTADOS FUENTE ELABORACIÓN PROPIA 


\section{Parámetros sociopolíticos}

Partiendo del concepto del espacio público como patrimonio social, la respuesta policial a actuaciones pacíficas quedaría fuera de la legalidad "colectiva". Siendo el primer instrumento disuasorio y de posterior intervención, las fuerzas de seguridad -u opresión, en los casos de ausencia democrática- reciben órdenes de disolver las protestas del espacio público alegando alteraciones del orden. El escenario resultante tiene una silueta dinámica y cambiante en relación directa con el hacer y el habitar la ciudad de cada cultura, pudiendo extraerse parámetros reales y directrices comunes para los regímenes dictatoriales, diferenciados claramente de las esferas democráticas. Esta distinción, así como la introducción del impacto del eco de la prensa internacional o el simbolismo político del espacio, son parámetros sugeridos por Fregonese (2013) para el ámbito europeo y por Irazábal (2008) en el estudio de los movimientos sociales latinoamericanos. Habiendo procedido a una actualización de sus contenidos y enfoques, se han valorado los siguientes parámetros sociopolíticos:

a. Estado del régimen: la debilidad o fortaleza del régimen dictatorial implica una forma masiva de manifestación en grandes espacios en el primero de los casos, y actuaciones aisladas en espacios menores en el segundo.

b. Simbolismo político: la reconquista por parte de los manifestantes de un espacio apropiado por el régimen hace del lugar un elemento público de disputa cuya ocupación supone de por sí un éxito, dada la carga ideogramática que conlleva.

c. Respuesta policial: desproporcionalidad en la dispersión de las protestas con el sucesivo incremento del apoyo a los manifestantes; el espacio se transforma en símbolo de las desigualdades.

d. Eco internacional: simbolismo o crudeza de las imágenes como garantía de visibilidad.
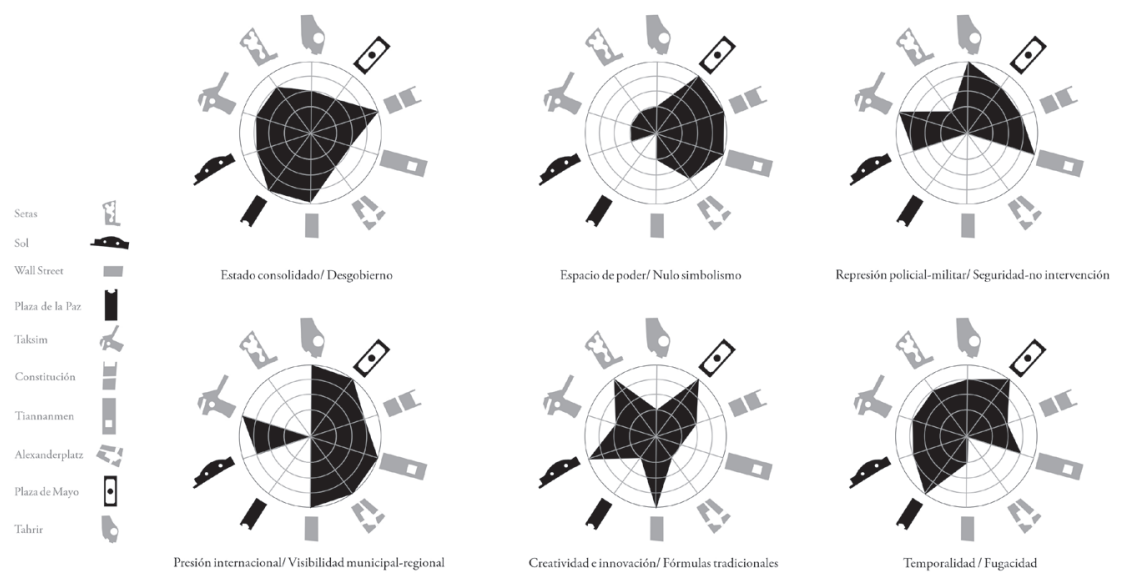

FIgURA 4 | Comparación de los casos de estudio según sus parámetros sociopolíticos

Nota EN NEGRo, LOS CASOS DE ESTUdio PRESENTAdos

FUENTE ELABORACIÓN PROPIA 
Existe una diferencia contrastada en la manera de habitar y, por lo tanto, de protestar el espacio público en relación con el sistema político establecido (Figura 4). Retomando la relación entre manifestantes y respuesta policial, se observa cómo la presión dictatorial convierte las protestas públicas en actos subversivos en los que el riesgo aumenta: lo público queda reducido al acatamiento estricto de unas normas unilaterales en las que la crítica y la contestación no están contempladas (Sánchez, 2017).

El espacio público pasa de ser el altavoz de la ciudadanía a escenario de representación del poder militar y político, por lo que cualquier alteración de su estado latente provoca que el efecto se duplique y que cualquier actividad se convierta en reseñable. Centrándonos en grandes concentraciones, se pueden verificar ciertas acciones que contrarrestan la imposibilidad de congregar a una cantidad importante de personas; similitudes entre las reivindicaciones desarrolladas en diversas dictaduras, independientemente de su localización geográfica. En primer lugar, parece crucial identificar el momento en el que se encuentra el régimen: las grandes concentraciones de personas se producen en etapas en las que el Estado presenta debilidad o está próximo a su caída, nunca en los años iniciales o posrepresivos tras conflictos civiles. Por el contrario, cuando hablamos de pequeños grupos de manifestantes, como el de las Madres de la Plaza de Mayo de Buenos Aires, la represión es inmediata y las concentraciones son disueltas sin obstáculos. ${ }^{2}$

Otro de los parámetros fundamentales necesarios de destacar en las reivindicaciones contra regímenes totalitarios es la necesidad de convocar grandes masas en espacios de considerables dimensiones; el efecto que debe producirse es el de una imagen de unanimidad y fuerza, como en cualquier manifestación pública. En el caso contrario, cuando las dictaduras se encuentran bien asentadas, las manifestaciones tienden a ser de tipo aislado, con el apoyo reciente de las redes sociales, donde acciones individuales retan la "pasividad" del espacio público (Sancho, 2018). En estos casos es la carga simbólica de la acción la que contrarresta la imposibilidad de congregar a una cantidad importante de personas.

Aunque de forma no intencionada, la simbología en el espacio público es fundamental y el "guion" casi teatral de las protestas puede acabar por ser el arma más potente. En el glosario de la historia contemporánea se encuentran imágenes icónicas, desde jóvenes bloqueando cańones con claveles a un hombre solitario frente a un tanque. Se trata de símbolos de la lucha por las libertades que sitúan el espacio público como soporte de las disputas. La imagen se convierte así en uno de los instrumentos reivindicativos más eficaces.

En el caso en que las manifestaciones se produzcan en Estados democráticos, los parámetros se ven alterados en fondo y forma. En primer lugar, el derecho de reunión, manifestación o huelga está permitido dentro de unos límites de seguridad y orden público, por lo que ocupar el espacio público de manera temporal es una acción común, no subversiva. Por ello se acentúa la variedad creativa en las representaciones reivindicativas; la necesidad de hacer visibles las reclamaciones

2 Una decena de personas relacionadas con el movimiento desaparecieron a los pocos días de la primera marcha frente a la Casa Rosada: se trató de la celebración del Mundial de Fútbol de 1978 en Argentina, lo que otorgaría repercusión a las Madres, haciendo sobrevivir las periódicas concentraciones. 
provoca que aparezcan fórmulas novedosas complementarias a las tradicionales, con pancartas, lemas, uso de objetos como símbolo (paraguas, luces, las mareas cromáticas, etcétera). Y al estar reconocido como un derecho fundamental, no es necesaria la congregación unánime de la sociedad civil. Cuando alcanzan un éxito moderado en visibilidad y número de manifestantes, las protestas se convierten en un instrumento capaz de presionar a los estamentos gubernamentales hasta su dimisión o disolución. De esta forma, las manifestaciones se han demostrado más numerosas en cantidad, aunque menos pobladas. En una relación directa, los espacios en los que se desarrollan, salvo excepciones, no llegan a la envergadura de las plazas y avenidas de las rebeliones contra regímenes totalitarios.

Cuando las protestas abandonan la vía pacífica, las fuerzas de seguridad también intervienen, aunque con respuestas diversas en función de cada Estado y en la mayoría de casos sin bajas civiles. Asumiendo que los puntos b), c) y d) pueden ser trasladados a este supuesto, aparecen dos nuevos parámetros diferenciales que se basan en la variedad y creatividad y la duración de las protestas:

e. Creatividad: alternativas en las formas de representación reivindicativa con la búsqueda de mayor repercusión.

f. Mayor duración de las protestas: campamentos o acampadas temporales.

A diferencia de los casos analizados en Estados dictatoriales, las protestas en democracia pueden llegar a adquirir un carácter duradero o periódico, transformando el espacio público en casi doméstico con las llamadas an-arquitecturas. La plaza se transforma, como en el caso de la Puerta del Sol madrileńa, en espacio de debate, biblioteca o dormitorio. Se trata de universalizar el espacio y hacer de las reclamaciones asunto colectivo, convirtiendo las protestas en algo íntimamente relacionado con lo público y su espacio.

\section{Parámetros de contorno urbano}

No podrían entenderse las protestas en la plaza de la Ciudadanía de Santiago de Chile sin la presencia inmediata del Palacio de la Moneda, o de la plaza de la Paz en Barranquilla sin el protagonismo de la Catedral María Reina. Los elementos urbanos que circundan los espacios en los que han estallado manifestaciones o revueltas confieren unos determinados componentes diferenciales a unas acciones reivindicativas que se ven alteradas por su hábitat más cercano.

Se observa cómo la arquitectura que envuelve las plazas establece vínculos bidireccionales con el vacío que encierra. A la vez que jerarquizan el espacio al señalarse como punto focal o núcleo en el flujo cotidiano, turístico o meramente funcional, los palacios presidenciales, mercados y sedes gubernamentales dinamizan y cualifican el espacio, al convertirlo potencialmente en soporte reivindicativo. En los casos que se han estudiado (Figura 5) se trata de edificios de tipologías con un alto grado simbólico: casas o palacios presidenciales (3), edificios gubernamentales (3), mercados (2), edificios civiles (1) y representación del poder económico (1).

Siguiendo los ejemplos analizados, el primer punto destacable de las relaciones entre unidad espacial pública y el conjunto de la urbis es la centralidad: 
en la mayoría de los ejemplos citados, las manifestaciones se producen en plazas y calles situadas en los centros históricos, estableciéndose conexiones comunes entre edificios representativos y una situación nuclear dentro de la ciudad. En el acercamiento de escalas, vemos cómo la accesibilidad a estos lugares suele repetirse a modo de patrón, a pesar de la variabilidad de los tejidos urbanos: se trata de calles o avenidas de tamaño considerable -en relación con el tamaño de cada ciudad- en las que se suceden zonas comerciales. Es lógico pensar, pues, en una secuencia centro comercio-plaza-edificio representativo.

El "régimen escalar periférico" (Navarro-de-Pablos, 2016) que las protestas alcanzan en un nuevo marco de expansión inmediata informativa través de las redes sociales, permite llevarlas a un doble plano, conceptual y virtual, con capacidad de replicarse rápidamente: uno de los ejemplos más clarificadores de la incidencia de las manifestaciones en sus respectivos entornos urbanos -partiendo desde el centro y llegando a la periferia- es, como hemos visto, el llamado Movimiento 15-M. Cuando la atmósfera sistémica permite las protestas en la calle, es fácilmente exportable a la periferia una determinada protesta en un determinado espacio público. De esta manera se crea una cadena en la que al núcleo original se engarza un sistema multipolar de protestas. Esta simbiosis centro-periferia es factible en aquellos ámbitos en que los desequilibrios son latentes y el uso del espacio virtual es parte del juego cotidiano.

En el cómputo de parámetros de contorno urbano que aparecen como patrones en el contexto de protestas urbanas, se podrían enumerar:

a. Simbolismo espacial: la relación del espacio-soporte y la posición que asume respecto de edificios u órganos de poder es directa, siendo siempre lugares adjuntos a casas o palacios presidenciales, núcleos políticos o civiles (mercados);

b. Cercanía a zonas comerciales: como resultado de la concatenación espacial centro-plaza-actividad comercial;

c. Régimen escalar periférico: o la capacidad de trasladar protestas y acciones a zonas periféricas o degradadas.
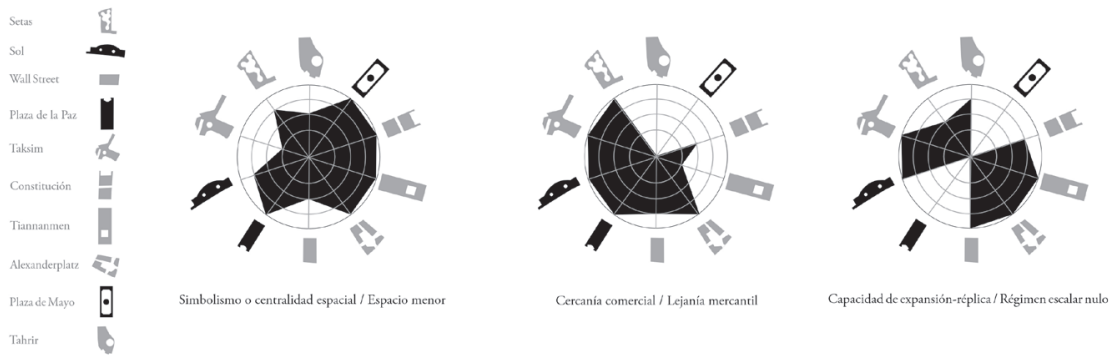

FIGURA 5 | Comparación de los casos de estudio según sus parámetros de contorno urbano

NOTA EN NEGRO, LOS CASOS DE ESTUDIO PRESENTADOS

FUENTE ELABORACIÓN PROPIA 


\section{Caso 1: La plaza de Mayo (Buenos Aires)}

Por la plaza de Mayo marchan diariamente las madres y abuelas de los desaparecidos durante la dictadura militar de Videla desde 1977 hasta 1981. Este hecho, acompañado de varias reivindicaciones sucesivas, la convierten en un espacio simbólico de marcada "memoria reivindicativa". El carácter de centralidad y simbolismo acompañan a este segmento urbano desde la fundación de la ciudad, construida en torno a un fuerte defensivo enclavado en la actual silueta Casa Rosada (Guerín, 1990). Ese cierto espíritu castrense de la plaza parece diluirse con el arranque de las protestas en 1977, cuando la ocupación del espacio respondía pacíficamente a una opresión militar.

Rompiendo aquella norma de las manifestaciones desencadenadas en regímenes dictatoriales por la cual se estima necesaria una gran concentración de personas y una puesta en escena coral, la marcha constante desafía a la autoridad de manera silente y disgregada. Analizando el contexto previo - golpe de Estado, toma militar, institución de la pena de muerte y desarticulación de las libertades-, en el caso de la plaza de Mayo podría preverse un desenlace basado en la dispersión de las manifestantes y una pena correspondiente por desórdenes públicos. Por el contrario, la rápida entrada de la difusión internacional frenó los mecanismos de respuesta del régimen: el objeto de protesta evidenciaba el desamparo de un colectivo civil vulnerable, hecho crucial para la consecución del compromiso y sensibilización de la comunidad internacional.

El caso de la plaza de Mayo constituye un paradigma gracias a una yuxtaposición de dos factores: en primer lugar, por la adaptación a las leyes de orden civil que impedían la concentración de personas en el espacio público, la cual fue contestada por las Madres moviéndose continuamente alrededor del obelisco central de la plaza a modo de rito sacro, sin poder ser acusadas de manifestación; en segundo lugar, por la construcción de una escenografía a través de un símbolo propio, una marca con la que identificarse y ser reconocidas, expresada a través de un pañuelo blanco. En las primeras concentraciones, los mandos militares no respondieron ante la novedad en la forma de protesta y el carácter pacífico de las mismas. Cuando el eco del movimiento comenzó a conquistar Buenos Aires, llegaron las primeras detenciones. Entre el jueves 8 de diciembre y el sábado 10 de diciembre de 1977, un grupo de militares bajo el mando de Alfredo Astiz secuestró a un grupo de doce personas vinculadas a las manifestantes (Bosco, 2006).

A los dos años, con el apoyo de Amnistía Internacional, las manifestantes viajaron a nueve países en los que fueron recibidas, en su mayoría, por jefes de gobierno. En ese momento, un movimiento que había comenzado con una decena de personas se había convertido en un fenómeno que congregaba a unas quinientas. Este hecho ejemplifica la singularidad del caso, que rompe con el patrón antes comentado, al tratarse de un grupo reducido congregado en un espacio de una superficie media, protestando ante una dictadura.

Examinando los resultados obtenidos del análisis paramétrico, se observa que el fenómeno orbita en torno a un momento crítico, cercano a un golpe de Estado, en que las protestas toman un eco internacional clave en su éxito y continuidad (Figura 6). Como se ha concluido en el análisis comparativo previo, el tenso clima 
social dentro de un Estado militar hizo más visible las concentraciones, fomentando su éxito. La concepción de la plaza como espacio cerrado y poco permeable, rodeado de un viario a modo de frontera y una serie de edificios de gran simbolismo, hacen que el entorno inmediato no consiga penetrar en su actividad diaria y la llevan a ser considerada como espacio urbano "habitable". La presencia de elementos circulares centrales como punto de atracción de las protestas, seguido de cuatro elementos secundarios (fuentes) que subconcentran el espacio, facilitan la creación de un sentimiento de pertenencia y un reconocimiento icónico.

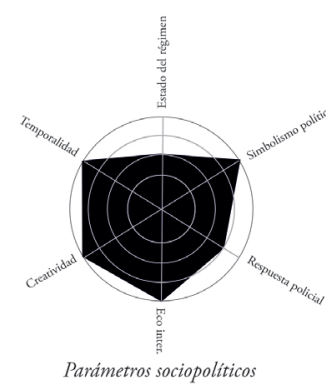

Se trata de un momento crítico, cercano a un golpe de estado y una dictadura recién instaurada cn la que las protestas toman un eco internacional clave en su éxito y continuidad. El tenso clima social dentro de un estado militar hace más visibles las concentraciones, por escaso seguimiento inicial que turicran.

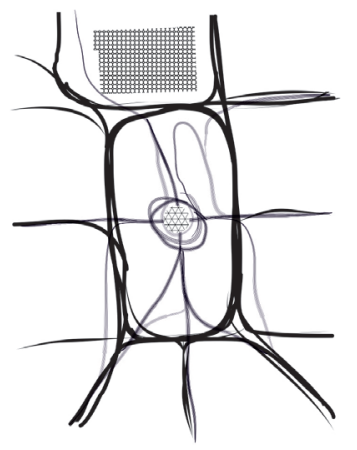

Intensidad y dirección de fujo

Existe una presencia predominante del flujo rodado, que encorseta el espacio público e impide la posibilidad de un recorrido continuo peatonal desde las principales avenidas adyacentes. El peatón describe direcciones dispersas y discontinuas por la disgregación espacial y los obstáculos de paso.

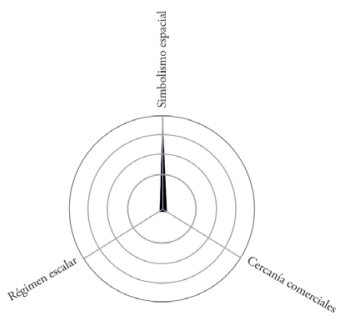

Parámetros de contorno urbano

La concepción de la Plaza como espacio cerrado y poco permeable, rodeado de un viario-barrera y una seric de edificios de gran simbolismo hacen que la escala de bario o entorno inmediato no consiga penetrar en su actividad diaria y ser considerada como espacio "habitable" desde el punto de vista urbano, ni cxtrapolablc a otras zonas por su singularidad simbólica.

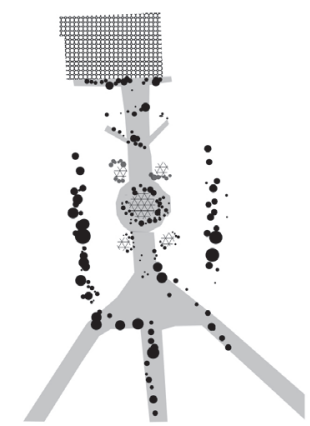

Ocupación cotidiana

La ocupación diaria se reduce al turismo y transeúntes de avanzada edad al rededor de la pirámide y las fuentes. La actividad comercia es inexistente, aunque la presencia de la Casa Rosada, la Bolsa, la Catedral y el Gobierno de la Ciudad hacen de la línea de fachadas que la delimitan un cinturón vivo pero ajeno al espacio público central.

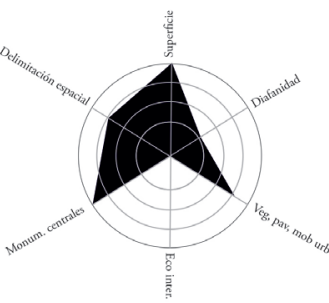

Parámetros espaciales

De nucvo aparece la capacidad de elementos circulares centrales como punto de atracción de las protestas, scguido de cuatro elementos secundarios (fuentes) que sub-concentran el espacio. El contenido espacial aparece

ordenado geométricamente pero disgregado y divido - fortuita o intencionadamente-, con una vegetación que sirven de barrera más que de sombra y escasísimas zonas de descanso.

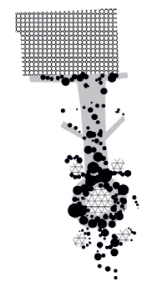

Ocupación reivindicativa

Clara concentración de la ocupación de protesta alrededor del símbolo espacial más. significativo, con forma circular que permite Alujos orbitales en su entorno.

FIGURA 6 | En la parte superior, estudio de los parámetros sociopolíticos, de contorno urbano y espaciales de la plaza de Mayo de Buenos Aires

NOTA EN LA PARTE INFERIOR, ANÁLISIS DE LAS DISTINTAS SITUACIONES DE OCUPACIÓN FUENTE ELABORACIÓN PROPIA 
El diseño decimonónico de la plaza la llena de islas de vegetación disgregada, de incómodas formas geométricas que respetan la potencia de la pirámide central, pero convierten su cota superficial en un lugar de difícil lectura y movimiento en el que no sería reconocible la unidad de una masa reivindicativa; como contrapeso de este hándicap, el escaso número de manifestantes guarda, a través del simbolismo y representación de las protestas, una carga más potente que la propia ordenación del espacio. La nula diafanidad de la plaza choca de bruces con el geocentrismo crítico de una manifestación pacífica: el éxito, pues, se encuentra en un fondo legítimo en contra de delitos contra la humanidad y en un pańuelo blanco.

A pesar de su nomenclatura, la plaza de Mayo no llega a ser entendida como espacio público de encuentro: en toda su extensión aparecen apenas seis bancos y bancadas alrededor de las cuatro fuentes, que junto a la planeidad del pavimento, sin variación significativa de cota, cierra la posibilidad de sentarse, recostarse o acampar. Esta componente de lugar ajeno a la escala y actividad humana se ve reforzada por el acceso a la plaza, constreñido a un viario de seis carriles y un intenso tráfico que embeben el recinto en una gran rotonda rectangular; una frontera de árboles en los flancos de las fachadas norte y sur arroja una sombra infructuosa, que contadas veces beneficia a las bancadas circulares que rodean las fuentes.

Con la entrada de la democracia y alegando motivos de seguridad, la plaza vive anudada a una presencia policial constante que quebranta la concepción unitaria del espacio a través de una barrera fronteriza que separa la parte más próxima a la Casa Rosada, de la pirámide central. Esta frontera física ejemplifica metafóricamente la realidad de unas fuertes desigualdades sociales y urbanas palpables a escala metropolitana, donde la repercusión del fenómeno fue evidente. No obstante, su extrapolación a zonas periféricas fue nula debido a la precariedad del espacio público de barrios como La Boca o San Martín, cuya ordenación y entorno no son asimilables al céntrico barrio de Montserrat y donde el simbolismo de sus plazas guarda más relación con el desequilibrio del reparto social que con las prácticas de los distintos regímenes políticos sucesivos.

A pesar del control policial y la dispersión periódica de las concentraciones, la plaza sigue siendo el escenario de mayor carga simbólica del país. El movimiento de las Madres y Abuelas de la Plaza de Mayo, que sirve de inspiración a los Encuentros Nacionales de Mujeres creados a finales de la década de los ochenta sigue siendo la referencia de la tradición de la militancia argentina (Montero, 2016) y de los crecientes movimientos feministas liderados por el colectivo de actrices de Hollywood a través del \#Metoo y la plataforma Time’s Up.

\section{Caso 2: Plaza de la Paz (Barranquilla)}

Desde su construcción en 1986, la plaza de la Paz en Barranquilla ha sido escenario de movilizaciones sociales. En Colombia, el contexto reivindicativo de las últimas décadas del siglo xx estuvo fuertemente marcado por el trasfondo de una debilidad en la construcción del Estado, desigualdades sociales, el agotamiento de los partidos tradicionales, la precariedad del activismo asociativo y un ulterior distanciamiento entre sociedad y clase política. Estos factores se vieron reforzados por el conflicto armado y el narcotráfico, fraguando un hastío social institucionalizado (Páramo et 
al., 2018). Con la llegada del siglo xxi, las manifestaciones pacíficas entraron en la actividad urbana del país de forma natural como resultado del proceso de diálogo con las guerrillas iniciado en 2012 (Muñoz, 2015), conformando un contexto propicio para la recuperación de los valores genéticos del espacio público citados en los primeros epígrafes del artículo.

En una de sus ciudades más importantes, Barranquilla, el centro de la actividad urbana, la plaza de la Paz, se ha convertido en un espacio considerado como de disputa y reivindicación, a pesar de ser el supuesto espacio sagrado asociado a la Catedral Metropolitana que la preside. La Universidad Libre y dos centros comerciales completan las fachadas que encierran la plaza, junto a las carreras 45 y 46 , arterias de comunicación y movilidad de la ciudad. Un filtro de vegetación cambia la escala urbana de estas dos grandes vías y acerca al peatón a la catedral, sobresaliente sobre el resto de las construcciones.

Los principales motivos de protesta acaecidas en la plaza se fundamentan en la reivindicación de los Derechos Humanos y el Derecho Internacional Humanitario, las conmemoraciones nacionales y locales y las condiciones laborales, habiéndose dado alrededor de cuarenta manifestaciones en los últimos cinco lustros. Las concentraciones en pro de los derechos fundamentales giraron, principalmente, en torno a la liberación de secuestrados por la guerrilla armada de las FARC, a las peticiones de paz y al respeto y cumplimiento de los Derechos Internacionales (Flores \& Escalante, 2005). En cambio, las conmemoraciones estuvieron relacionadas con días señalados, como el Día del Trabajo, Día de la Mujer o Día de la Juventud. Asimismo, se han recogido concentraciones en memoria de líderes políticos, intelectuales y de lucha, como los homenajes realizados por Carlos Pizarro en 1992 o Guillermo Cano en 1987.

Las protestas organizadas en torno a las condiciones laborales representan las luchas obreras clásicas, surgidas de las relaciones tradicionales de desequilibrios entre producción, productividad y reparto de la riqueza. Entre las manifestaciones realizadas por este motivo se encuentra la Protesta Nacional llevada a cabo en 1999 contra el Plan de Desarrollo impulsado por el expresidente Andrés Pastrana. Estas expresiones, de un carácter más local que el resto de casos y eximidas del carácter de capitalidad urbana -a diferencia de lo ocurrido en Buenos Aires o Madrid-, significaron una visibilización de las luchas cotidianas. La plaza de la Paz ejemplifica lo que Tejerina (2005) presentará como "motivos cotidianos", es decir, espacios dados a una ocupación de bajo impacto y de manifestación casi ritual.

El principal actor social de las protestas ocurridas en la plaza de la Paz ha sido la ciudadanía, proveniente de la propia ciudad costera o de poblaciones cercanas del área metropolitana. El segundo colectivo que más manifestaciones ha protagonizado es el de los desempleados, con siete protestas, a las que siguen las concentraciones o mítines convocados por los principales partidos políticos de Colombia. Aunque es la Catedral Metropolitana de María Reina el edificio que preside la plaza, en escasísimas ocasiones se trata de manifestaciones relacionadas con aspectos religiosos, entendiéndose que la fuerza de convocatoria que subyace es la de hito urbano. En 2012 se reformó la plaza, pasando de un único plano a estar dividida en dos cotas; se incorporaron sombras y vegetación en la zona semienterrada, quedando las proximidades de la catedral liberadas de mobiliario urbano. Es precisamente la densificación 
de la zona norte la que permite que la sur sea el escenario óptimo para la visibilidad de manifestaciones y la concentración de un mayor número de personas.

Uno de los hechos diferenciales de este caso, además del carácter de "símbolo cotidiano", es un contexto mediático en el que el periodismo disfruta de unos niveles de aceptación mundialmente reconocidos, destacando la radio como medio de consumo masivo; de hecho, la mayoría de las protestas y manifestaciones suelen tener difusión a través de este medio, compitiendo de forma directa con la nube virtual. Estos medios y la ciudadanía movilizada, en un tándem simbiótico natural (Fernández Droguett, 2011), construyen un espacio público físico-radiofónico que permite visibilizar las protestas, consolidando la acción de reivindicar como un acto crítico, maduro y colectivo. Este hecho marca una legitimación institucional de las protestas sociales, por la cual el hecho "subversivo" de ocupar un espacio público se convierte en un acto consciente y justificado, al tratarse de una empresa colectiva; los individuos que participan en las concentraciones pertenecen a diversos sectores sociales, poseen diferentes perspectivas respecto a temas comunes y experimentan distintos sentimientos, descontentos y anhelos frente a una misma realidad, pero aun así participan activamente de una misma acción. Es decir, poseen vínculos identitarios heterogéneos y solo momentáneamente, al encontrarse en la plaza, los suspenden para potenciar aquello que los une durante la protesta.

Analizando los datos dimanantes de la aplicación metodológica (Figura 7), se puede determinar que se trata de un contexto de democracia consolidada y un Estado de Bienestar en evolución ascendente, donde se dan unas protestas enmarcadas dentro de la normalidad cotidiana en un espacio representativo del poder civil. Espacialmente, las concentraciones se localizan en un área anexa a la catedral como centro de gravedad simbólico, aunque están desprovistas de religiosidad y son reconocidas en su mayoría como manifestaciones con fondo político y social. Es precisamente su centralidad urbana -gracias al hito catedralicio, que llega a regir el pavimento y ordenación espacial del vacío- lo que provoca una nula repercusión en otras zonas de la ciudad, al polarizar el simbolismo ciudadano. La reordenación reciente de la plaza limita el número de manifestantes congregados, pero mejora su cualidad espacial al introducir vegetación e implementar la integración de servicios sociales en una entreplanta.

Las componentes de carácter político-social que rodean la plaza se conjugan con una formalización espacial determinada. De forma rectangular, el espacio se divide en dos: un área cercana a la catedral, cuyo pavimento continúa la arquitectura de la seo dibujando formas geométricas alargadas, apuntando al eje este-oeste que ocupa el espacio público; y la parte más al este junto a la Calle 50, cuya reciente remodelación ha servido para incluir una nueva cota, más baja, a la plaza. La ruptura de la unidad del espacio con esta última intervención impide la concentración de un mayor número de manifestantes, a pesar de que las protestas que acoge no suelen acumular densidades altas de personas.

La plaza de la Paz constituye, así, un ejemplo claro de éxito de un espacio público provincial como lugar de protesta. Suponiéndole un cierto carácter museístico, turístico o sagrado, la plaza es indiscutiblemente el altavoz popular municipal, resultado de una ecuación verificada: una escala adecuada, una vegetación que sirve 
de línea definitoria y el acompañamiento de un clima político, periodístico y social equilibrado que permite el normal desarrollo de la actividad reivindicativa.

Es precisamente este clima de normalidad el que le priva de adquirir un relieve internacional e incluso nacional, a pesar del compromiso de los medios con los diferentes agentes sociales que se manifiestan. Además de las protestas a nivel social, la plaza de la Paz actúa como condensador de actividades relacionadas con conmemoraciones, actos de partidos políticos o actividades culturales, devolviendo a la normalidad una actividad íntegramente urbana, la de disfrutar en y con la ciudad, en contraposición a la tendencia privatizadora del espacio público extendida en los regímenes democráticos.

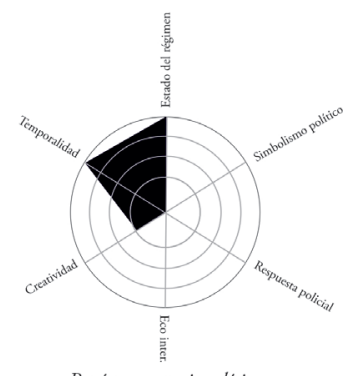

Parámetros sociopolíticos

Democracia consolidada $y$ Estado de Bienestar en evolución ascendente. Protestas enmarcadas dentro de la normalidad cotidiana en un espacio representativo del poder civil.

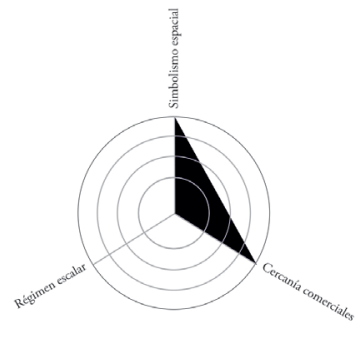

Parámetros de contorno urbano

Espacio anexo a la caredral como hecho circunstancial, mayoría de manifestaciones con fondo político y social. Nula repercusión en otras zonas de la ciudad al polarizar el simbolismo ciudadano y centro de actividad.

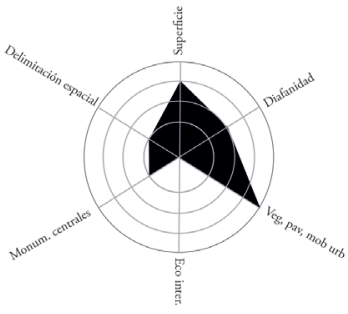

Parámetros espaciales

Reordenación reciente de la plaza que limita el número de manifestantes congregados pero mejora cualidad espacial. Mayor vegetación e integración de servicios sociales en una entreplanta. Presencia de la catedral rige pavimento $y$ ordenación.

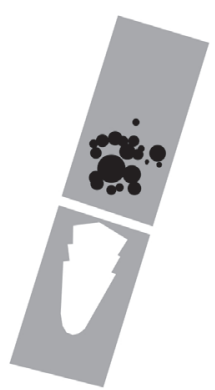

Ocupación reivindicativa

La división entre catedral y plaza a través de la Calle 53 impide una ocupación del espacio inmediato a la catedral, al igual que el desnivel de la mitad este impide su ocupación total, reduciéndose el espacio de protesta a la explanada central.

FIGURA 7 | En la parte superior, estudio de los parámetros sociopolíticos, de contorno urbano y espaciales de la plaza de la Paz de Barranquilla

NOTA EN LA PARTE INFERIOR, ANÁLISIS DE LAS DISTINTAS SITUACIONES DE OCUPACIÓN FUENTE ELABORACIÓN PROPIA 


\section{Caso 3: Puerta del Sol (Madrid)}

Al igual que el caso bonaerense, la Puerta del Sol constituye un ejemplo de resimbolización contemporánea, siguiendo la estela de manifestaciones y revueltas pretéritas -Motín de Esquilache (1766) o Levantamiento del 2 de Mayo (1808)-. El embrión de esta resignificación arranca con el distanciamiento del centro de poder y la ciudadanía, una distancia que se acrecienta paulatinamente hasta que el 15 de mayo de 2011 los llamados "indignados" acamparon en el interior de la plaza. Desde el 1 de abril de ese año se venía gestando una serie de protestas de distintos colectivos civiles con una cabeza visible, la asociación Democracia Real Ya, inspirada en la revuelta griega de 2008 .

La primera manifestación organizada por la plataforma concluyó en la madrugada del 16 de mayo, cuando las Fuerzas de Seguridad desalojaron de la Puerta del Sol a los asistentes que seguían allí congregados desde un día anterior. Al día siguiente se volvieron a concentrar unas 10.000 personas. Tras un nuevo desalojo, el fenómeno se reprodujo en las principales plazas del país, llegándose a registrar hasta 211 acampadas-protesta. En estos primeros días de la "Acampada Sol" se decidió permanecer como mínimo hasta las elecciones municipales del 22 de mayo y comenzar un proceso participativo ciudadano, que transformaría paulatinamente las manifestaciones en asambleas populares abiertas celebradas en plazas o parques y estructuradas en diversas comisiones -legal, comunicación, acción, actividades, barrios, estatal e internacional, información, infraestructuras, lenguas de signos- y grupos de trabajo.

La cercanía temporal con las elecciones y la espacial con el Congreso de los Diputados, hicieron que la Puerta del Sol y el Movimiento 15 de Mayo sirvieran de catalizadores del hartazgo ciudadano ante las políticas austeras del gobierno socialista, regidas por los mercados y otros gobiernos europeos. Con la concepción de una soberanía perdida, el "Kilómetro 0" situado en la Puerta del Sol representaba el objetivo principal del colectivo manifestante: una regeneración profunda de la democracia española.

Prohibidas pero toleradas, las acampadas eclipsaron la campaña y los mítines finales de los líderes nacionales hasta el mismo día de las elecciones; el protagonismo anónimo de la Puerta del Sol consiguió mantenerse tras el cambio de gobierno, ante la ausencia de cambios en el sistema político y la continuidad en los recortes sociales. El carácter abierto, semicircular y sin límites -obstáculos- espaciales se conjugó con los valores promovidos por los convocantes. De nuevo fue alrededor de dos elementos circulares simétricos, un par de fuentes, donde se concentraron, como si de un imán gravitatorio se tratase, las primeras estructuras con carácter temporal.

Destacan la centralidad de un hito representado en la estatua ecuestre de Carlos III, que hace las veces de reposadero y/o mirador, y una forma característica en planta que crea una sensación de diafanidad, sin perder la delimitación del espacio a escala humana. Estas dos características, el abrigo perimetral semicircular y una referencia monumental en su centro, conforman una suerte de atalaya urbana propia, protectora. Partiendo de este sistema bicentrípeto, la amplitud de la plaza da cabida, con una alta densidad, hasta a unas 120.000 personas, incrementables gracias a las diez calles que desembocan en ella. 
Aunque en el principal edificio de la plaza se halle la Presidencia de la Comunidad de Madrid, la memoria colectiva relaciona el valor de "Sol" como concepto con las protestas de 2011. Esta asociación significa el cambio en la percepción simbólica de la plaza, siendo con total seguridad el escenario futuro de nuevas movilizaciones.

En este contexto repleto de alarmantes síntomas de un sistema en vías de ruptura con el orden establecido, aparece una simbiosis interesante entre espacio y ocupación; es una generación mayoritariamente joven la que, sin perspectivas de futuro, se lanza de forma de crítica y segura a la conquista del espacio público. Una vez ocurrida la pérdida del miedo a dejar atrás un estatus prometido, pero nunca alcanzado, el espacio público emerge como primer refugio de acogida ciudadana.

A pesar de las evidentes deficiencias económicas y políticas de un movimiento eminentemente ciudadano -posteriormente cristalizado en una corriente política que parece capaz de condensar ciertas mayorías-, y de las brechas discursivas dentro de un planteamiento de ruptura con las garantías democráticas conocidas, el 15M triunfó y consiguió ocupar un espacio público físico durante un periodo importante, y de manera atemporal en la memoria de las revoluciones, estableciendo una simbiosis vital entre Puerta del Sol e indignados.

Si a través de la lectura de las etiquetas en diversas redes sociales en esos meses previos a las elecciones de 2011 se puede entender a la perfección las cimas y valles de las convocatorias (Rodríguez, 2011), el análisis de cómo se ocupa el espacio y su evolución en el tiempo hacen análogamente entender el fenómeno desde un punto de vista urbano y arquitectónico (Figura 8).

La decena de calles que desembocan en la Puerta del Sol poseen un carácter eminentemente comercial, con la encrucijada de las calles Mayor, Preciados y Carrera de San Jerónimo como punto gravitacional de la ciudad. El edificio que preside la plaza de manera continua antes de la existencia de la misma es un simple telón de fondo, el escenario en el que no se centran las protestas: más que un punto de atención fijo, las proclamas silenciosas y sentadas se dirigen al aire; la Comunidad de Madrid, residente del Palacio de Correos, es una institución incluida en el amplio gramaje de estamentos protestados, que no llega a alcanzar la importancia de una convocatoria que reclama un cambio sistémico.

Las circunstancias diferenciales de las protestas del 15-M estuvieron determinadas por un gobierno democrático estable, aunque gravemente afectado por la crisis económica de 2008, cristalizada en recortes sociales, el aumento de la carga impositiva y una merma en el Estado del Bienestar (Iglesias-García et al., 2017). El descontento con la situación de privilegio de los bancos y entidades financieras y el crecimiento del desempleo aparecen como las causas principales del estallido reivindicativo.

El fenómeno se expandió rápidamente, y a los pocos días se instalaron acampadas en Barcelona, Valencia, Sevilla, Zaragoza, Málaga o Bilbao, ampliándose el campo de colectivos implicados; como una exitosa representación teatral, la efectiva escenificación de la obra se adaptó a diversos escenarios y tramoyas. Planteando una igualdad total desde la base -un sentido horizontal de la forma de hacer, actuar y expresarse-, la protesta tenía cabida en cualquier lugar, población y desde cualquier colectivo con idénticos objetivos. En esa democratización de las manifestaciones, se 
apelaba a un cierto heroísmo patriótico - de una nación más virtual que territorial-, una "ilusión" que avivaba aún más la sensación de tener la capacidad de hacer frente al régimen democrático establecido.

El entusiasmo por el éxito de las convocatorias virtuales constituyó un elemento clave para la consolidación del movimiento. Estudios como los de Gerbaudo (2016, p. 268), que permite analizar distintas cartografías de la incidencia de las redes sociales entre los participantes, sirven para contrastar cómo la proyección de una imagen positiva y exitosa en la esfera virtual aumentó exponencialmente la ocupación de los espacios físicos. Sirvió, además, de complemento de los primeros estudios en torno al papel de Twitter en el 15-M, como el de Peña-López, Congosto y Aragón (2014), o los de García-Hípola y Beltrán Rodríguez (2013), investigación pionera sobre la traslación de la esfera virtual a la realidad física y las volátiles fronteras entre legalidad e ilegalidad.

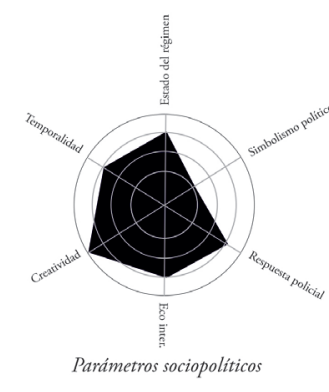

Gobierno democrático estable afectado por grave crisis internacional. Recorres sociales y fuerte carga impositiva. Desempleo extremo como causa principal de un descontento generalizado. Grandes masas de

manifestantes en espacio significativos de todas las ciudad del país.

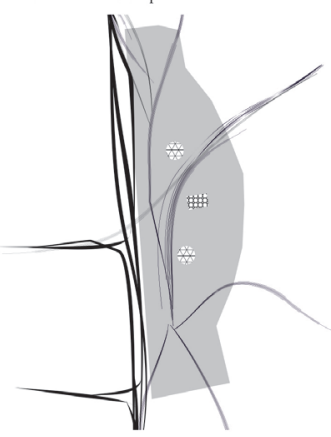

$$
\text { Intensidad y dirección de fujo }
$$

Flujo intenso de movimiento desde la calle Preciados hacia y desde las bocas de metro situadas en las partes inferior $y$ superior del esquema; tránsito limitado a taxis y autobuses en el flanco del edificio de Correos.

Parámetros propios de cruce de caminos y no de ágora urbana.

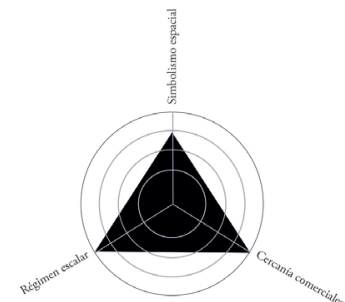

Parámetros de contorno urbano

Crucial presencia de actividades comerciales generadoras de flujos y realidad cotidiana. Espacio con capacidad para formar parte de un régimen escalar de reperición que exporta modelo reivindicativo a periferia, ciudades nacionales e internacionales.

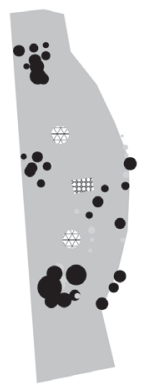

Ocupación cotidiana

Focalización en torno a las dos bocas de metro y la fachada comercial de la parte oblonga; escasa ocupación duradera. Concentración de turismo en $\mathrm{km} 0 \mathrm{y}$ estatua ecuestre.

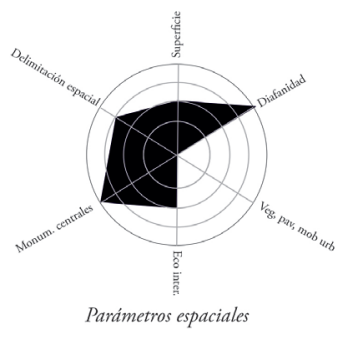

Centralidad de un hito/monumento y una forma característica en planta. Sensación de diafanidad y delimitación del espacio suficiente para crear una suerte de atalaya urbana propia.

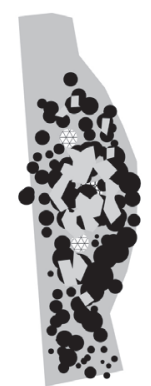

Ocupación reivindicativa

Centralización de la ocupación bajo el monumento ecuestre y las fuentes circulares. Establecimiento de estructuras efímeras en torno al mismo punto con independencia y dispersión proporcionalmente a su alejamiento.

FIGURA 8 | En la parte superior, estudio de los parámetros sociopolíticos, de contorno urbano y espaciales de la Puerta del Sol de Madrid

NOTA EN LA PARTE INFERIOR, ANÁLISIS DE LAS DISTINTAS SITUACIONES DE OCUPACIÓN FUENTE ELABORACIÓN PROPIA 
El caso del 15-M no solo repite el modelo de protesta ocurrido en otras ciudades, sino que es capaz de fagocitar los modelos reivindicativos de las periferias; aunque de forma paulatina, las asociaciones vecinales empiezan a repensar su manera de hacer uso de sus herramientas de diálogo y ocupación del espacio bajo su tutela. Esta realidad, a veces tomada como generalización indebida, describe una necesaria regeneración, desde la base, del concepto de democracia y transparencia en el uso de la propia ciudad.

En el caso madrileńo, al igual que en la plaza de la Encarnación de Sevilla o la plaza de Cataluńa de Barcelona, existe una presencia de actividades comerciales generadoras de flujos en su perímetro que supone un contrapunto a la realidad cotidiana: esos comercios, al igual que el tránsito peatonal diario, se ven interrumpidos por la ocupación. La Puerta del Sol es un espacio con capacidad de exportar su ocupación en un régimen escalar de repetición, trasladando su modelo reivindicativo a las periferias tanto a escala urbana (barrios del área metropolitana), como a escala nacional (ciudades de provincia).

La ruptura con las reglas establecidas, que hace de la Puerta del Sol un ecosistema tanto social, con una agenda cultural de actuaciones y charlas propias; como político, con estructura asamblearia; e incluso económico, con la instauración del trueque como forma de pago, la convierte en un hito ideológico. En el uso y el habitar del espacio público significado por la Puerta del Sol se rompe con su génesis fundacional: si fue un punto de cruce y paso, con una actividad cotidiana de ocupación fugaz -cuenta de ello es la ausencia de bancos, puntos de reposo, vegetación o puntos de abastecimiento de agua-, se transformó en un campo base consolidado en la ruta hacia el mántrico "cambio". Hasta entonces, las concentraciones que reclamaban modificaciones en el sistema político poseían un formato tradicional de marcha, con una cabeza de cartel y pancartas con un lema unificado y claro. En Sol, la aparición de arquitecturas efímeras dio a entender la voluntad de prolongación en el tiempo.

La consolidación del 15-M llegó con la fuerte carga policial empleada para el desalojo de las concentraciones pacíficas de la Acampada Sol, aumentando su eco internacional. La corriente indignada, tras el desalojo y elecciones del 24 de mayo, no cesó de convocar nuevas acciones, planteando una logística más madura y enfocada a una visibilidad mayor con menores recursos: micromanifestaciones, asambleas, performances y acampadas diarias dibujan el mapa activista del país desde entonces, habiéndose diluido, a la vez que se ha consolidado, un proyecto político dentro del sistema.

\section{Conclusiones: ¿̨hacia un modelo global?}

Tanto el estudio comparativo de las dispersas y diversas realidades en torno a la ciudad, el espacio público y la acción reivindicativa, como su profundización en los tres casos expuestos del arco iberoamericano, ofrecen unos principios de cierta incontestabilidad: en primer lugar, es reseñable cómo la contestación autoritaria y la coacción a las libertades - de expresión, huelga o manifestación- redundan en una lectura errónea de la concepción posmoderna del espacio público como lugar 
pasivo, cotidiano, rutinario; de hecho, reafirman los postulados de Salcedo-Hansen (2002), según los cuales la reivindicación es inherente a las sociedades urbanas y, como vector independiente a las características formales del espacio, resulta contraproducente su dispersión u omisión. Desde su aparición en la ciudad grecolatina, el espacio público es un lugar de convergencia, encuentro y reflexión en el que las sociedades -entendidas como la aleación de poderes civiles, políticos, económicos y culturales- son capaces de disputar a través de la dialéctica: es decir, se trata de un elemento estructural que no puede ser obviado ni borrado de la trama urbana ni de la esfera política. Este principio se ve acrecentado por la presencia de los espacios de contestación virtuales, que suponen el refugio inmediato en atmósferas sociales en las que el espacio físico está vedado a la representación oficialista. Parece claro, tal y como se deduce de los parámetros analizados en la Figura 4 (gráficos 3 y 4), que cuanto mayor sea el ímpetu por hermetizar los espacios de poder, mayor es la contestación: los espacios más reprimidos desembocan en reivindicaciones con un eco internacional exponencialmente superior. Esta circunstancia dibuja un fenómeno similar al que emerge con la colocación de monumentos centrales, en su mayoría vallados, en los centros físicos de las plazas con el fin de obstaculizar concentraciones, convirtiéndose paradójicamente en puntos gravitacionales sobre los que orbitan los manifestantes. Esta hipótesis se construye a partir de la yuxtaposición de los datos comparados de la Figura 5, y de los análisis pormenorizados de la Figura 6, Figura 7 y Figura 8, en las que se visibiliza cómo la colocación de estos elementos es una estrategia fallida seguida de forma global en el intento por proteger estos espacios públicos icónicos de posibles ocupaciones. De hecho, estos hitos centrales no suponen objetos reseñables en el tránsito cotidiano, activándose como jalones una vez que las plazas son ocupadas de forma transitoria y reivindicativa.

Seguidamente se puede deducir un factor común en la puesta en escena de los tres casos iberoamericanos analizados, como es la capacidad de producir nuevos lugares e identidades en un ejercicio de relectura del paisaje urbano, llevando a los convocantes a construir unos símbolos reconocibles asociados a las demandas reclamadas. Estos productos podrían asociarse a un nuevo urban branding, revisado recientemente por Zenker (2018), en el que los símbolos sustituyen el papel del mensaje: en los casos tanto de la plaza de Mayo como de la Puerta del Sol (véase Figura 4), la creatividad es un elemento clave para la consecución de una mayor repercusión mediática, a la vez que se teje un entramado de pertenencias a un movimiento o colectivo determinado. A pesar del potencial del pańuelo blanco de las Madres o las asambleas asociativas condensadas a través de un círculo de color púrpura del $15-\mathrm{M}$, la construcción del relato posee una clara raíz física que impide deslindar la reivindicación de plaza. Confirmando esta hipótesis, la plaza de la Paz de Barranquilla, huérfana de símbolos visuales diferenciados, sigue constituyendo el referente departamental de lucha. Aunque la relación entre manifestación y espacio parezca indisoluble, sí existe una componente novedosa a la hora de expandir las proclamas: las simbologías de Madrid y Buenos Aires, apoyadas en unas redes tecnológicas que han acortado distancias y tiempos, son capaces de expandirse a otros entornos periféricos e internacionales en un tránsito en el que, de nuevo, el mensaje toma el relevo del simbolismo. 
En tercer lugar, existe un vector que aparece con fuerza en la significación de estos espacios como lugares-altavoz. Más allá de la propia simbología heredada de los edificios que presiden los espacios, por norma general emerge la componente comercial como polo de atracción de las manifestaciones. Resulta concluyente observar cómo los lugares cercanos a áreas comerciales se convierten en áreas de mayor actividad reivindicativa: las causas podrían estar relacionadas con la cercanía, el conocimiento colectivo, la accesibilidad y una posible fuente de recursos y avituallamiento. Este planteamiento se apoya en el cruce de los datos paramétricos resultantes de temporalidad y cercanía comercial: en aquellas ocupaciones de larga duración se acortan las distancias con áreas mercantiles.

Dentro de la disparidad de tramas urbanas comparadas planteadas en el inicio del artículo, sobresalen diferencias destacadas derivadas de la realidad física de cada caso: si bien en los contextos de Madrid (véase Figura 8) la presencia del tráfico rodado se encuentra en un proceso de decrecimiento en favor del peatón, la presencia del viario infraestructural en los casos de Buenos Aires (véase Figura 6) o Barranquilla (véase Figura 7) suponen una barrera importante a la hora de entender estos grandes vacíos urbanos como parte de la trama urbana. El archipiélago de islas surcadas de vehículos de la ciudad difusa (Melo, 2016) no propicia una ocupación natural de la ciudad. Puede observarse cómo en las plazas tratadas desde una perspectiva humanistica, conectadas a la ciudad consolidada peatonalmente, las manifestaciones se desarrollan con mayor normalidad y la ciudadanía se apropia de los elementos existentes como si de un espacio doméstico colectivo se tratase. Entendiendo como inevitable el proceso de apertura de los espacios públicos como lugares de diálogo y confrontación, y su contraproducente privatización, la mirada urbanística en el proyecto de ciudad debería ser sensible a la realidad social a la que da cabida. Con la postura multidisciplinar que conlleva la arquitectura, su implantación en el territorio y la ordenación del mismo, parece difícil encajar la perpetuación de modelos urbanos en los que el tráfico rodado sigue prevaleciendo sobre el tránsito peatonal. En el desarrollo de la investigación se refuta cómo espacios ocluidos por vías de tráfico de vehículos tienen propensión a quedar reducidos a residuos de descanso y recreo, sin aprovechar la sinergia de lo público en la actividad cotidiana de las ciudades.

En relación con el análisis de las circunstancias espaciales interiores de estos espacios rebeldes, se hace posible determinar, a partir de las gráficas comparativas, algunas ecuaciones de éxito que contribuyen a la realización de las proclamas convocadas; así, el tratamiento ordenado y racional de la vegetación, del mobiliario urbano y del pavimento parece estar proporcionalmente relacionado con el sentimiento de pertenencia y apropiación de la plaza. Se observa al respecto que los espacios definidos proyectualmente son más reconocibles y, por consiguiente, tienen más posibilidades de ser elegidos como espacios-altavoz. En las relaciones entre diseño urbano y ocupación, las componentes sensitivas que ofrece el espacio son claves para entender la relación con los estados de ánimo del colectivo. Se ha podido evidenciar cómo en situaciones diáfanas, pero rodeadas de murallas vegetales o elementos delimitadores, se anula el potencial de las grandes concentraciones a la vez que, en espacios sin una delimitación espacial clara, ya sea por su superficie o por la ausencia 
de alguna de sus fachadas, converge una sensación de segregación que diluye su potencia expansiva, según se extrae de la comparativa entre la capacidad replicadora de las protestas y la diafanidad de los espacios reivindicativos (Figura 3, gráfico 2 vs. Figura 5, gráfico 3).

$\mathrm{Al}$ intentar desvelar algunos vectores diferenciales en los casos de Iberoamérica, surge la dificultad de acotar un fenómeno global a ciertas circunstancias culturales específicas, tal y como concluye Rafail (2018) en un estudio análogo de la ciudad de Nueva York. Tenemos, así, que los tres casos estudiados muestran similitudes en los factores temporales (remiten a reivindicaciones extendidas en el tiempo y de carácter periódico), en el fuerte simbolismo de sus espacios (Casa Rosada, Comunidad de Madrid, Catedral de María Reina, Palacio de La Moneda o Mercado de la Encarnación) y en la creatividad de sus expresiones (del pañuelo blanco al círculo morado). Al mismo tiempo, otros casos internacionales convocados en el análisis comparativo muestran niveles paramétricos similares, lo que nos lleva a pensar en la definición de un fenómeno que ha asumido los procesos de globalización sistémicos en su relación con el espacio físico, aun sin renunciar a los simbolismos y expresiones locales.

La globalidad del fenómeno, una de las conclusiones nucleares que se ha podido desentrańar, viene a actualizar parcialmente los supuestos de Brenner y Theodore (2002) en cuanto a la asociación exclusiva del término 'liberalismo' a zonas de fuerte presencia capitalista, como Norteamérica o Europa. En las casi dos décadas que han transcurrido desde la publicación del texto, parece claro que ha tenido lugar la homogeneización del contexto global, donde el neoliberalismo ha trazado una compleja red de ramificaciones virtuales de alcance e impacto aún desconocido. Incluso así, ha aumentado la presencia y vigencia de las protestas - "instrumentos privilegiados", tal y como las describía Lefebvre (1968) - en los espacios potencialmente altavoz, trazando una paradójica parábola de intereses cruzados entre la propiedad colectiva de lo público y el asentamiento neoliberal de las lógicas urbanas. La citada revolución de las redes sociales, lejos de poner en riesgo la supervivencia del espacio público como soporte reivindicativo, parece servir de instrumento previo de creación de corrientes y movimientos.

Con el objetivo último de construir una herramienta de estudio para las futuras representaciones reivindicativas que aguardan, la metodología expuesta abre un espectro analítico que podría ser aplicado, con la suficiente perspectiva temporal e histórica, a los procesos de reivindicaciones feministas, el resurgimiento de los nacionalismos y populismos o la volatilidad y dispersión del asociacionismo. El esparcimiento de parámetros y contextos, unido al aumento de la contestación urbana, confirman cómo ese "derecho a la ciudad", habiendo cumplido cinco décadas, sigue siendo un derecho dinámico, volátil y universal que requiere de un constante análisis y revisión. 


\section{Referencias bibliográficas}

Barret-Kriegel, B. (1989). L'État et les esclaves: réflexions pour lihistoire des États (vol. 4). París: Payot.

Bosco, F. J. (2006). The Madres de Plaza de Mayo and three decades of human rights' activism: Embeddedness, emotions, and social movements. Annals of the Association of American Geographers, 96(2), 342-365. https://doi.org/ 10.1111/j.1467-8306.2006.00481.x

Brenner, N. \& Theodore, N. (2002). Spaces of neoliberalism: Urban restructuring in Western Europe and North America. Londres: Blackwell.

Chevallier, J. (2015). El Estado de derecho. Bogotá: Universidad del Externado de Colombia.

Escalada, J. E. \& Castro, L. T. (2016). La comunicación y las relaciones públicas en los operativos de intervención policial de control de masas. Revista Internacional de Relaciones Públicas, 6(12), 147-168. https://dialnet.unirioja.es/servlet/articulo?codigo=5769822

Fernández Droguett, R. (2011). Política y espacio público: ciudadanía radical en manifestaciones conmemorativas. Revista de Arquitectura - Universidad de Chile, (24), 5-10. https:// doi.org/10.5354/0719-5427

Flores, P. \& Escalante, K. (2005). La «plaza de la paz» y el diario «el heraldo» como espacios públicos de la protesta social en Barranquilla (Colombia). Investigación y desarrollo, 15(2), 342-363. https://doi.org/10.5354/0719-0905.2017.47339

Fregonese, S. (2013). Mediterranean geographies of protest. European Urban and Regional Studies, 20(1), 109-114. https://doi.org/10.1177\%2F0969776412460528

García-Hípola, M. G. \& Beltrán Rodríguez, M. (2013). Acción vs representación: el 15-M y su repercusión en la ciudad. Ángulo Recto: Revista de estudios sobre la ciudad como espacio plural, 5(1), 5-26. https://webs.ucm.es/info/angulo/volumen/Volumen05-1/ articulos $01 . h \mathrm{tm}$

Gehl, J. (2014). Ciudades para la gente. Buenos Aires: Infinito.

Gerbaudo, P. (2016). Constructing public space / Rousing the Facebook crowd: digital enthusiasm and emotional contagion in the 2011 protests in Egypt and Spain. International Journal of Communication, 10(20), 254-273. https://ijoc.org/index.php/ ijoc/article/view/3963

Guerín, M. A. (1990). Los comercios de Buenos Aires, sus orígenes y su incidencia en la urbanización. Summa temática, (34-35), 70-77.

Harvey, D. (2012). Las raíces urbanas de las crisis financieras: reclamar la ciudad para la lucha anticapitalista. En M. Belil, J. Borja \& M. Corti (Eds.), Ciudades, una ecuación imposible (pp. 321-358). Barcelona: Icaria.

Iglesias García, C., Sáiz, P. A., Burón, P., Sánchez-Lasheras, F., Jiménez-Trevino, L., FernándezArtamendi, S., Al-Halabí, S., Corcorán P., García-Portilla, M. P. \& Bobes, J. (2017). Suicidio, desempleo y recesión económica en Espańa. Revista de Psiquiatría y Salud Mental, 10(2), 70-77. https://doi.org/ 10.1016/j.rpsm.2016.04.005

Irazábal, C. (2008). Ordinary places/extraordinary events: citizenship, democracy and public space in Latin America. Londres: Routledge.

Lefebvre, H. (1968). Le droit à la ville (vol. 3). París: Anthropos.

Melo, J. B. (2016). Transporte verde y ciudad sustentable. Revista Bio-grafía Escritos sobre la biologia y su enseñanza, Extraordinario, 224-231. https://doi.org/10.17227/bio-grafia. extra2016-6338 
Monreal, P. (2016). Ciudades neoliberales: ¿el fin del espacio público? Una visión desde la Antropología urbana. Quaderns-e de l'Institut Català d'Antropologia, 21(1), 98-112. https://bit.ly/3clgR9U

Montero, A. S. (2016). Política y convicción. Memorias discursivas de la militancia setentista en el discurso presidencial argentino. Revista Latinoamericana de Estudios del Discurso, 7(2), 91-113. http://dx.doi.org/10.35956/v.7.n2.2007.p.91-113

Muñoz, C. A. G. (2015). Diálogos de paz Gobierno-farC-eP y las oportunidades para la paz en Colombia. Estudios Políticos, (46), 243-261. https://dialnet.unirioja.es/servlet/ articulo? codigo $=5263722$

Navarro-de-Pablos, J. (2016). El espacio público como soporte reivindicativo y las estrategias para reclamar el patrimonio colectivo: el caso de la plaza Taksim en Estambul. $P H$ : Boletín del Instituto Andaluz del Patrimonio Histórico, 24(90), 198-201. https://doi. org/ 10.33349/2016.0.3815

Páramo, P., Burbano, A., Jiménez-Domínguez, B., Barrios, V., Pasquali, C., Vivas, F. \& Moyano, E. (2018). La habitabilidad del espacio público en las ciudades de América Latina. Avances en Psicología Latinoamericana, 36(2), 345-362. http://dx.doi.org/10.12804/ revistas.urosario.edu.co/apl/a.4874

Peña-López, I., Congosto, M. \& Aragón, P. (2014). Spanish Indignados and the evolution of the $15 \mathrm{M}$ movement on Twitter: towards networked para-institutions. Journal of Spanish Cultural Studies, 15(1-2), 189-216. https://doi.org/10.1080/14636204.201 4.931678

Rafail, P. (2018). Protest in the city: Urban spatial restructuring and dissent in New York, 19602006. UrbanStudies, 55(1),244-260.https://doi.org/10.1177\%2F0042098016661464

Rodríguez, E. M. F. (2011). El movimiento 15-M y su evolución en Twitter. TELOS 89: Redes sociales y democracia, (89), 61-73. https://telos.fundaciontelefonica.com/archivo/ numero089/el-movimiento-15-m-y-su-evolucion-en-twitter/

Salcedo Hansen, R. (2002). El espacio público en el debate actual: Una reflexión crítica sobre el urbanismo post-moderno, EURE, 28(84), 5-19. http://dx.doi.org/10.4067/S025071612002008400001

Sánchez, F. A. (2017). Aproximaciones a una salida a la distinción espacio público y privado. Una pregunta por un Otro Espacio. Nomadias. Feminista, (23), 127-142. https://doi. org/10.5354/0719-0905.2017.47339

Sancho, G. R. (2018). El devenir feminista de la acción colectiva: las redes digitales y la política de prefiguración de las multitudes conectadas. Teknokultura, 15(2), 223-240. https:// doi.org/10.5209/TEKN.59367

Sevilla-Buitrago, A. (2015). Urbanismo, crisis y austeridad. Ciudades, (18), 31-48. https://doi. org/10.24197/ciudades.18.2015

Sitte, C. (1980). Construcción artística de las ciudades. Barcelona: Gustavo Gili.

Tejerina, B. (2005). Movimientos sociales, espacio público y ciudadanía: Los caminos de la utopía. Revista Crítica de Ciências Sociais, (72), 67-97. https://doi.org/10.4000/ rccs. 982

Torre, M. I. D. L. (2015). Espacio público y colectivo social. Nova Scientia, 7(14), 495-510. https://doi.org/10.21640/ns.v7i14.74

Zenker, S. (2018). City marketing and branding as urban policy. Cities, (80), 1-3. https://doi. org/10.1016/j.cities.2018.06.001 